\title{
HUKUM MEROKOK PADA KEADAAN IHRAM BESERTA IMPLIKASINYA DALAM IBADAH HAJ DAN UMRAH
}

\author{
Sayyid Tashdyq \\ Sekolah Tinggi Ilmu Islam dan Bahasa Arab (STIBA) Makassar \\ abbanaaisyah@gmail.com \\ Muhammad Syahrir \\ Sekolah Tinggi Ilmu Islam dan Bahasa Arab (STIBA) Makassar \\ muhammadsyahrir889@gmail.com \\ Abdil Munzir \\ Sekolah Tinggi Ilmu Islam dan Bahasa Arab (STIBA) Makassar \\ abdilmunzir@stiba.ac.id
}

Keywords
Law, Smoking, Ihram, Hajj,
Umroh

\begin{abstract}
Among the bad habits that are often witnessed during the implementation of the Hajj and Umrah are smoking, the smoke is very disturbing comfort of the people around, especially done in the area of al-Haram, masyarilharam even in 'arafah. Though the Prophet Sallallaahu 'Alaihi wa Sallam has given good news in the form of Paradise for those who hajj mabrur. Therefore, it is necessary to study the impact of smoking on the Hajj or Umrah. This research uses library research method by collecting references relating to the object of study, heuristic approach through personal experience, normative approach in breaking down the law of ihram in the Hajj and Umrah, and the methodology is descriptive analysis. The results of this study stated that smoking is haram, so that it includes violations in berihram which can have an impact on reducing the culprit's reward, and it is feared not to reach a hajj that is mabrur, or umrah that maqbulah on the side of Allah Subhanahu wa Ta'ala. Although it does not affect the validity of worship as long as the harmony and its requirements are met. For this reason, it is desirable for active smokers to abandon this bad habit, especially when carrying out the Hajj and Umrah, as well as the mentors to always remind their congregants not to commit these violations. We recommend reprimanding and advising them when found violating these directives to stop in order to get the virtue of this noble worship with the permission of Allah Subhanahu wa Ta'ala.
\end{abstract}

ABSTRACT

\begin{tabular}{ll}
\hline Kata kunci & \multicolumn{1}{c}{ ABSTRAK } \\
\cline { 2 - 3 } Hukum, Merokok, Ihram, Umrah. & Di antara kebiasaan buruk yang sering disaksikan pada saat \\
pelaksanaan ibadah haji dan umrah adalah merokok, asapnya \\
sangat mengganggu kenyamanan orang sekitar, apalagi dilakukan \\
di daerah al-haram, masyarilharam bahkan di 'arafah. Padahal \\
Nabi Shallallahu 'Alaihi wa Sallam telah memberikan kabar \\
gembira berupa surga bagi yang hajinya mabrur. Oleh karena itu, \\
perlu dikaji dampak merokok tersebut terhadap ibadah haji atau \\
umrah. Penelitian ini menggunakan metode kajian pustaka \\
(library research) dengan mengumpulkan referensi-referensi yang \\
\hline
\end{tabular}


BUSTANUL FUQAHA: Jurnal Bidang Hukum Islam

Vol. 1, No. 3 (2020) : Hal. 330-349

Website: https://journal.stiba.ac.id

berkaitan dengan obyek kajian, pendekatan heuristik melalui pengalaman pribadi, pendekatan normatif dalam mengurai hukum ihram dalam haji dan umrah, serta metodologinya bersifat analisis deskriptif. Hasil dari kajian ini menyatakan bahwa merokok itu haram, sehingga termasuk pelanggaran dalam berihram yang bisa berdampak pada pengurangan pahala pelakunya, dan dikhawatirkan tidak meraih haji yang mabrur, atau umrah yang maqbulah di sisi Allah Subhanahu wa Ta'ala. Meskipun tidak sampai mempengaruhi keabsahan ibadahnya selama terpenuhi rukun dan syarat-syaratnya. Untuk itu, sangat diharapkan bagi para perokok aktif untuk meninggalkan kebiasaan buruk ini, terutama saat melaksanakan ibadah haji dan umrah, begitu pula kepada para pembimbing agar senantiasa mengingatkan jemaahnya untuk tidak melakukan pelanggaran ini. Sebaiknya menegur dan menasehati mereka disaat kedapatan melanggar arahan tersebut untuk berhenti agar bisa mendapatkan keutamaan dari ibadah yang mulia ini dengan izin Allah Subhanahu wa Ta'ala. 
BUSTANUL FUQAHA: Jurnal Bidang Hukum Islam

Vol. 1, No. 3 (2020) : Hal. 330-349

Website: https://journal.stiba.ac.id

\section{PENDAHULUAN}

Ibadah haji merupakan rukun Islam yang kelima, diwajibkan atas setiap muslim, balig, berakal, dan berkemampuan fisik dan harta untuk menunaikannya, sebagaimana perintah Allah Subhanahu wa Ta'ala dalam al-Qur'an,

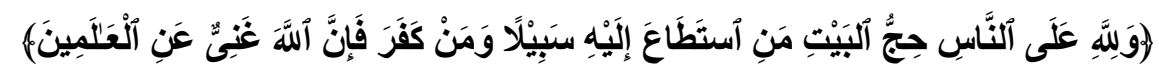

Terjemahnya: “...Dan (di antara) kewajiban manusia terhadap Allah adalah melaksanakan ibadah haji ke Baitullah, yaitu bagi orang-orang yang mampu mengadakan perjalanan ke sana. Barangsiapa mengingkari (kewajiban) haji, maka ketahuilah bahwa Allah Maha Kaya (tidak memerlukan sesuatu) dari seluruh alam.” (Q.S. Ali Imran/3: 97).

Dan dalam hadis, Rasulullah Shallallahu 'Alaihi Wasallam bersabda,

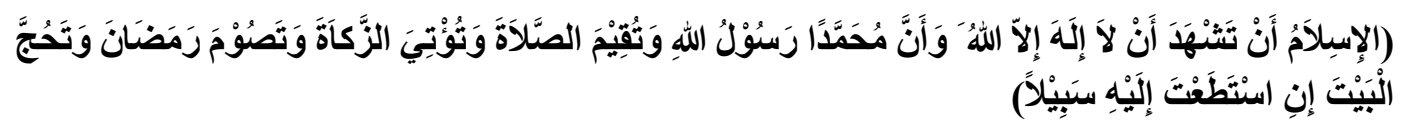

Artinya: "Islam adalah kamu bersaksi bahwa tidak ada sembahan yang berhak disembah selain Allah, dan bahwa Muhammad adalah utusan Allah, kamu mendirikan shalat, menunaikan zakat, puasa Ramadhan, dan menunaikan ibadah haji jika kamu mampu."1

Ibadah haji ini memiliki banyak keistimewaan, di antaranya:

1. Dari Abu Hurairah radhiyallahu 'anhu, bahwasanya Rasulullah Shallallahu 'Alaihi wa Sallam bersabda,

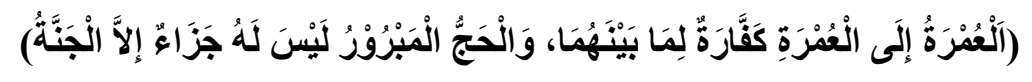

Artinya: "Umrah ke umrah berikutnya sebagai penghapus dosa antara keduanya, dan haji yang mabrur tidak ada pahala baginya selain surga."2

2. Dari Ibnu Mas'ud radhiyallahu 'anhu, bahwasanya Rasulullah Shallallahu 'Alaihi wa Sallam bersabda,

${ }^{1}$ Muslim Bin Al-HajjajAn-Naisaburi. Shahih Muslim. Kitab Al-Iman, Bab Al-Iman Wa Al-Islam Wa Al-Ihsan, Nomor 8. Beirut: Darul Kutub Al-'Ilmiyah, 1414H.

2 Muhammad Bin IsmailAl-Bukhari.Shahih Al-Bukhari, Abwab Al-'Umrah, Bab Wujub Al-'Umrah Wa Fadhliha, Nomor 1773. Dar Thariq An-Najah, 1422H. Dan An-Naisaburi, Muslim Bin Al-Hajjaj. Shahih Muslim. Kitab AlHajj, Bab Fi Fadhli Al-Hajj Wa Al-'Umrah Wa Yaum 'Arafah. Nomor 1349. Beirut: Darul Kutub Al-'Ilmiyah, 1414H. 


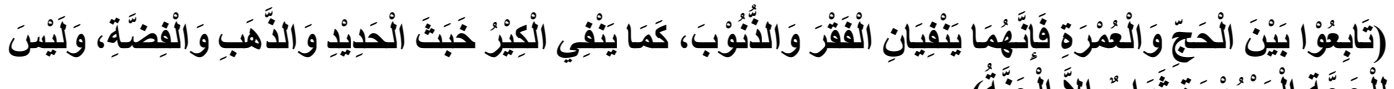

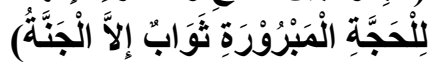

Artinya: "Iringilah antara ibadah haji dan umrah karena keduanya meniadakan dosa dan kefakiran, sebagaimana alat peniup api menghilangkan kotoran (karat) besi, emas dan perak, dan tidak ada balasan bagi haji mabrur melainkan surga."3

3. Dari Abu Hurairah radhiyallahu 'anhu, dia berkata, "Aku mendengar Nabi Shallallahu 'Alaihi wa Sallam bersabda,

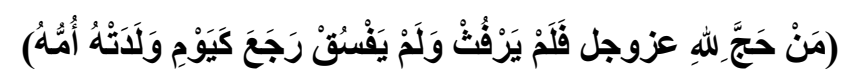

Artinya: "Barangsiapa melakukan haji ikhlas karena Allah Azza wa Jalla tanpa berbuat keji dan kefasikan, maka ia kembali tanpa dosa sebagaimana waktu ia dilahirkan oleh ibunya."4

4. Ibadah haji termasuk jihadnya para wanita sebagaimana dalam hadis:

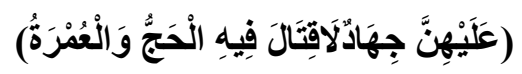

Artinya: "Bagi mereka (wanita) jihad yang tidak ada peperangan di dalamnya, yaitu haji dan umrah"5

Oleh karena kedudukan dan keistimewaan ibadah ini, maka kita saksikan kaum muslimin dan muslimah berlomba-lomba untuk menunaikannya walaupun harus antre bertahun-tahun lamanya. Bagi mereka yang merasa terlalu lama menunggu antrean, maka mereka akan melakukan ibadah umrah terlebih dahulu, yang juga merupakan kewajiban bagi seorang muslim yang mampu. Namun disayangkan, tidak sedikit mereka yang berangkat tidak membekali diri dengan ilmu tentang ibadah tersebut, sehingga begitu banyak terjadi kesalahan-kesalahan bahkan pelanggaran-pelanggaran syariat, baik dalam masalah akidah, akhlak, maupun yang berkaitan langsung dengan ibadah tersebut.

Allah Ta'ala berfirman,

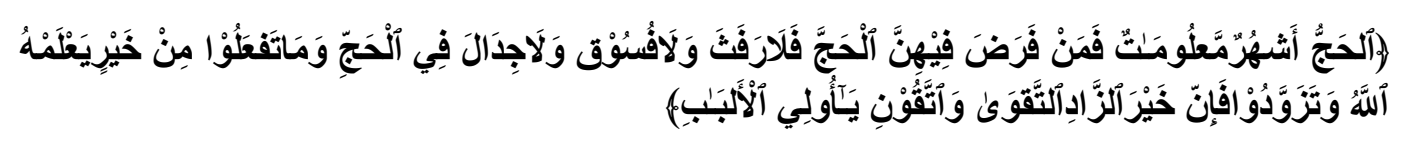

${ }^{3}$ Muhammad bin 'IsaAt-Tirmidzi, Sunan At-Tirmidzi, Abwab Al-Hajj 'An Rosulillah Shallallahu 'Alaihi Wa Sallam, Bab Ma Jaa Fi Tsawabi Al-Hajj Wa Al- 'Umrah, Nomor 810. Cet 2: Mesir, Syarikah Musthofah, 1395H

${ }^{4}$ Muhammad Bin IsmailAl-Bukhari, Shahih Al-Bukhari, Kitab Al-Hajj, Bab Fadhl Al-Hajj Al-Mabrur, Nomor 1521.Dar Thariq An-Najah, 1422H.

${ }^{5}$ Muhammad Bin YazidAl-Qozwini. Sunan Ibnu Majah, Kitab Al-Manasik, Bab Al-Hajj Jihad An-Nisa, Nomor 2910.Kairo: Dar Ihya Al-Kutub Al-Arabiyah, 2009. 
Terjemahnya: "(Musim) haji adalah beberapa bulan yang dimaklumi, barangsiapa yang menetapkan niatnya dalam bulan itu akan mengerjakan haji, maka tidak boleh rafas, berbuat fasik dan berbantah-bantahan di dalam masa mengerjakan haji. Dan apa yang kamu kerjakan berupa kebaikan, niscaya Allah mengetahuinya. Berbekallah, dan sesungguhnya sebaik-baik bekal adalah takwa dan bertakwalah kepada-Ku hai orang-orang yang berakal.” (Q.S. Al-Baqarah/2: 197).

Bisa jadi mereka yang melakukan pelanggaran-pelanggaran tersebut tidak mendapatkan kesempurnaan dalam ibadahnya, atau bahkan menggugurkan semua pahalanya tanpa mereka sadari. Padahal mereka telah mengorbankan banyak harta, waktu dan tenaganya untuk dating menunaikannya. Adapun di antara fenomena yang sering penulis saksikan adalah sebagian jemaah merokok dalam keadaan berihram, umrah atau haji. Lalu apa hukum merokok itu? Apakah termasuk pelanggaran saat ihram? Apakah dapat membatalkan ibadah haji atau umrah?.

Ibnu 'Allaan Al-Bakriy As-Shiddiiqiy Asy-Syaafi'i (wafat $1057 \mathrm{H}$ ) telah menulis sebuah kitab khusus tentang pengharaman rokok, yang beliau beri judul "Pemberitahuan Kepada Saudara-Saudaraku Akan Haramnya Merokok". Begitu pula dengan penelitian terdahulu yang pernah membahas berkaitan dengan penelitian ini, di antaranya Muhammad Ronnurus Shiddiq yang membahas Fatwa MUI tentang hukum rokok. ${ }^{6}$ Tujuan dari penelitian tersebut yaitu untuk mengetahui dasar hukum yang digunakan oleh MUI dalam mengeluarkan fatwa pengharaman rokok. Hasil dari penelitian tersebut yaitu bahwa penetapan fatwa haram merokok hanya bagi ibu hamil, anak-anak dan merokok di tempat umum.

Adapun dalam penelitian ini, penulis ingin mengkhususkan hukum merokok saat berhaji atau berumrah. Selain peneliti di atas, Erwandi Tarmizi juga pernah membahas permasalahan rokok di dalam bukunya "Harta Haram"7, di mana beliau menjelaskan hukum jual beli rokok dengan menyebutkan beberapa pendapat, dan beliau memilih pendapat yang mengharamkannya. Khusunya dalam penelitian ini, penulis juga membahas masalah hukum merokok, namun dengan tujuan untuk mengetahui keabsahan ibadah haji atau umrah yang dilakukan sang perokok aktif.

Selanjutnya peneliti yang mempunyai relevansi pada penelitian ini adalah Supardi dengan judul penelitian "Merokok Dan Transaksi Jual Beli Rokok dalam Pandangan Hukum Islam." ${ }^{8}$ Dari hasil penelitian tersebut, penulis mencoba untuk mempertegas dan menggali sumber-sumber hukum yang berkaitan dengan aktivitas merokok serta sekaligus menjelaskan hukum memperjualbelikan rokok

${ }^{6}$ Ronnurus,Muhammad S.,Fatwa Majelis Ulama Indonesia tentang Pengharaman Merokok, Skripsi UIN Sunan Kalijaga Yogyakarta (2009).

${ }^{7}$ Erwandi Tarmizi. Harta Haram Muamalat Kontemporer. Bogor:PT.Berkat Mulia Insani. (2017)

Yogyakarta (2009)

${ }^{8}$ Supardi, Merokok dan Transaksi Jual Beli Rokok dalam Pandangan Hukum Islam,Skripsi UIN Sunan Kalijaga 
tersebut. Namun, tentunya penelitian tersebut tidak menyinggung masalah dampak merokok saat melakukan ibadah haji dan umrah, sehingga dalam penelitian ini memfokuskan hal tersebut.

Selain itu, Muchtar A.F. telah menyajikan buku yang berjudul "Siapa Bilang Merokok Makruh?"9 dengan memaparkan manfaat dan mudarat rokok. Adapun dalam penelitian ini memaparkan pandangan beberapa ulama tentang merokok di saat beribadah haji atau umrah.

Metodologi yang digunakan dalam penelitian ini adalah metode kepustakaan (library research) yaitu dengan mengumpulkan pendapat-pendapat para ulama Islam terdahulu maupun kontemporer, serta dari literatur-literatur dan karya pustaka lainnya yang berhubungan dengan obyek kajian, dengan data primer yang bersumber dari Al-Qur'an dan hadis. Adapun penelitian ini juga menerapkan pendekatan heuristik melalui pengalaman pribadi penulis atas pencerapan terhadap fenomena umat yang merokok tatkala sedang melaksanakan haji dan umrah, serta pendekatan normatif dalam mengurai hukum merokok dalam berihram haji dan umrah. Untuk analisis penelitian, sifatnya deskriptis-analisis, yaitu usaha untuk mendeskripsikan suatu gejala dan peristiwa dengan apa adanya secara sistematis.

\section{PEMBAHASAN}

\section{Hukum Merokok}

Tidak dapat dipungkiri lagi bahwa rokok memiliki unsur-unsur dan zat-zat yang sangat berbahaya. Di antara bahan baku rokok adalah tembakau, dan lebih dari 3040 jenis bahan kimia yang dijumpai dalam daun tembakau yang sudah kering, dan di dalam rokok yang sedang dihisap oleh si perokok atau disebut juga asap utama "mainstream smoke", terdapat sekitar 400 jenis bahan kimia, ${ }^{10} 200 \mathrm{di}$ antaranya berbahaya terhadap kesehatan manusia. ${ }^{11}$ Adapun asap rokok yang keluar dari ujung rokok yang terbakar disebut asap sampingan "sidestream smoke". Senada dengannya Le, dkk., menyatakan bahwa "sidestream cigarette smoke, the major component of environmental tobacco smoke, is a complex and reactive aerosol, the particulate matter (PM) in sidestream smoke is one of the carriers of chemical constituents."12 Dari pernyataan tersebut, tampak bahwa asap rokok mengandung zat kimia berbahaya bagi kesehatan.

${ }^{9}$ Muchtar A. F., Siapa Bilanng Merokok Makruh?, Jakarta: PT Bhuana IlmuPopuler, 2009.

${ }^{10}$ Mangku Sitepoe, Kekhususan Rokok Indonesia, Jakarta: PT Gramedia, 2000,hal 25.

${ }^{11}$ Muhammad Jaya, Pembunuh Berbahaya Itu Bernama Rokok, Yogyakarta: Rizma, 2009.hal 49

${ }^{12} \mathrm{Li}$, X., Lin, B., Zhang, H., Xie, F., Ta, N., Tian, L., ... \& Xi, Z. (2016). Cytotoxicity and mutagenicity of sidestream cigarette smoke particulate matter of different particle sizes. Environmental Science and Pollution Research, 23(3), 2588-2594. 
BUSTANUL FUQAHA: Jurnal Bidang Hukum Islam

Vol. 1, No. 3 (2020) : Hal. 330-349

Website: https://journal.stiba.ac.id

Hal ini juga dibenarkan oleh Hammado melalui penelitiannya bahwa merokok dapat menyebabkan penyakit bronkitis atau radang cabang tenggorok, jantung koroner, trombosis koroner, kanker, dan kematian pada janin, ${ }^{13}$ serta gangguan atau penurunan kualitas spermatozoa. ${ }^{14}$ Dengan demikian, merokok tampak sangat berbahaya bagi kesehatan pribadi dan orang di sekitarnya.

Cukuplah dengan apa yang sering kita saksikan di iklan-iklan rokok tertulis peringatan "merokok membunuhmu", “dapat menyebabkan kanker", dan kata-kata seram lainnya, yang disertai dengan gambar menakutkan. Begitu pula yang tertulis di dinding-dinding rumah sakit atau puskesmas "matikan rokok anda sekarang sebelum rokok mematikanmu". Itu semua disebut dengan "Pictorial Health Warning" (PHW), yang merupakan salah satu upaya pemerintah dalam mereduksi cara pandang dan perilaku merokok masyarakat Indonesia. ${ }^{15}$

Adapun di dalam syariat Islam, Allah Ta'ala melarang hamba-hamba-Nya untuk melakukan hal-hal yang bisa membinasakan diri, sebagaimana yang disebutkan di dalam Al-Qur'an,

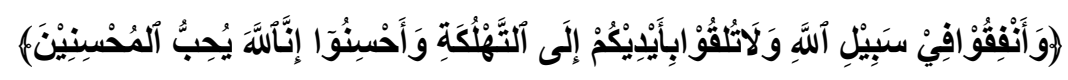

Terjemahnya: "Janganlah kamu jatuhkan (diri sendiri) ke dalam kebinasaan dengan tangan sendiri, dan berbuat baiklah. Sungguh, Allah menyukai orang-orang yang berbuat baik." (Q.S. Al-Baqarah/ 2:195).

Dari sabda Nabi Shallallahu 'Alaihi wa Sallam dari Ibnu Abbâs radhiyallahu 'anhu,

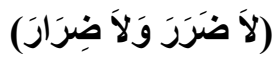

Artinya: "Tidak boleh melakukan sesuatu yang membahayakan diri sendiri ataupun orang lain."16

Allah Ta'ala juga memerintahkan kita agar memakan makanan yang baik dan mengharamkan bagi kita sesuatu yang buruk,

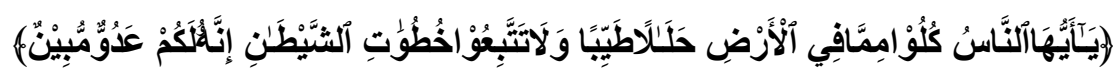

\footnotetext{
${ }^{13}$ Hammado, N. "Pengaruh Rokok Terhadap Kesehatan dan Pembentukan Karakter Manusia." Prosiding 1.1 (2014): 77-84

${ }^{14}$ Batubara, I. V. D., Wantouw, B., \& Tendean, L. (2013). Pengaruh paparan asap rokok kretek terhadap kualitas spermatozoa mencit jantan (mus musculus). eBiomedik, 1(1).

${ }^{15}$ Samosir, D. S. N., Priyatna, C. C., \& Hafiar, H. (2019). Makna Pictorial Health Warning Pada Kemasan Rokok Dalam Mengomunikasikan Pesan Bahaya Merokok. Jurnal Nomosleca, 5(1).

${ }^{16}$ Ahmad Bin HanbalAs-Syaibani. Musnad Al-Imam Ahmad. Musnad Al-Anshar, Hadits Ubadah Ibn AshShamit, Nomor 22779 Beirut: Muassasah Ar-Risalah,1421H.
} 
BUSTANUL FUQAHA: Jurnal Bidang Hukum Islam

Vol. 1, No. 3 (2020) : Hal. 330-349

Website: https://journal.stiba.ac.id

Terjemahnya: "Wahai manusia! Makanlah dari (makanan) yang halal dan baik yang terdapat di bumi, dan janganlah kamu mengikuti langkah-langkah setan. Sungguh, setan itu adalah musuh yang nyata bagimu." (Q.S. Al-Baqarah/2: 168).

Dalam ayat yang lain berbunyi,

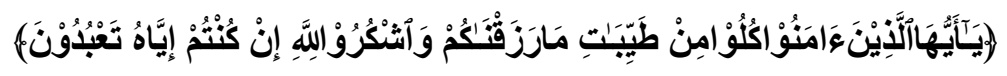

Terjemahnya: "Wahai orang-orang yang beriman! Makanlah dari rezeki yang baik yang Kami berikan kepada kamu dan bersyukurlah kepada Allah, jika kamu hanya menyembah kepada-Nya." (Q.S. Al-Baqarah/2: 172).

Dalam ayat yang lain berbunyi,

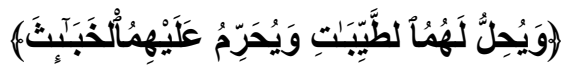

Terjemahnya: "...Dan yang menghalalkan segala yang baik bagi mereka dan mengharamkan segala yang buruk bagi mereka...” (Q.S. Al-A'raf/7: 157).

Dalam ayat yang lain berbunyi,

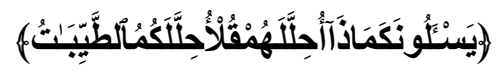

Terjemahnya:"Mereka menanyakan kepadamu: "Apakah yang dihalalkan bagi mereka?". Katakanlah: "Dihalalkan bagimu yang baik-baik" (Q.S. Al-Maidah/5: $4)$.

Allah Ta'ala juga melarang kita berbuat boros, karena membeli rokok adalah suatu hal yang sia-sia, yang membuat kita berlaku boros, dalam Al-Qur'an disebutkan,

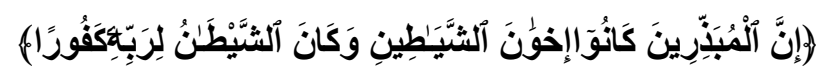

Terjemahnya: "Sesungguhnya orang-orang yang pemboros itu adalah saudara setan dan setan itu sangat ingkar kepada Tuhannya". (Q.S. Al-Isra/17: 27)

Dari uraian di atas dapat disimpulkan bahwa merokok itu hukumnya haram, dan minimal makruh. Ada yang berpendapat bahwa merokok hukumnya boleh dengan dalil segala sesuatu itu hukum asalnya mubah kecuali terdapat larangan, berdasarkan firman Allah Ta'ala,

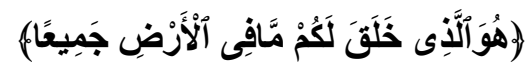

Terjemahnya: "Dialah (Allah) yang menciptakan segala apa yang ada di bumi untukmu...” (Q.S. Al-Baqarah/2: 29). 
Ayat di atas menjelaskan bahwa segala sesuatu yang diciptakan Allah Ta'ala di atas permukaan bumi ini adalah halal untuk manusia, termasuk tembakau yang digunakan untuk bahan baku rokok. Namun, dalil ini tidak menunjukkan kehalalan rokok, karena segala sesuatu yang diciptakan Allah hukumnya halal bila tidak mengandung hal-hal yang merusak, sebagaimana firman Allah Ta'ala,

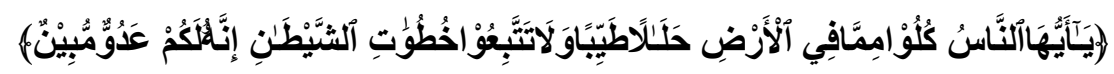

Terjemahnya: "Wahai manusia! Makanlah dari (makanan) yang halal dan baik yang terdapat di bumi, dan janganlah kamu mengikuti langkah-langkah setan. Sungguh, setan itu musuh yang nyata bagimu”. (Q.S. Al-Baqarah/2: 168).

Sedangkan tembakau mengandung nikotin yang secara ilmiah, dan kesepakatan ahli medis, telah terbukti merusak kesehatan dan bisa membunuh penggunanya secara perlahan.

Adapun pendapat 4 Imam Mazhab tentang hukum merokok, dan tentang pengharaman rokok itu sendiri diuraikan sebagai berikut:

\section{Mazhab Hanafi}

Menurut mazhab Hanafi merokok hukumnya haram. Ulama mazhab Hanafi yang menyatakan demikian di antaranya adalah Syaikh Muhammad al-'Aini. Alasan keharaman merokok mencakup 4 hal, yaitu:

1. Rokok terbukti dapat membahayakan kesehatan sebagaimana telah dibuktikan oleh para pakar medis.

2. Rokok termasuk jenis barang yang memabukkan dan dapat melemahkan tubuh, walaupun kadarnya kecil tetap dilarang mengkonsumsinya.

3. Bau yang ditimbulkannya tidak sedap dan dapat menyebabkan sakit bagi orang lain yang tidak merokok.

4. Merokok dianggap sebagai suatu tindakan pemborosan, tidak berfaedah, bahkan justru mendatangkan resiko. Sikap demikian dilarang oleh agama.

Menurut sebagian ulama Hanafiyyah, segala sesuatu pada dasarnya diharamkan kecuali terdapat dalil yang menjelaskan kebolehannya, hal ini sesuai dengan kaidah fikih:

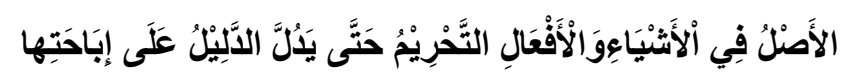

Artinya: "Hukum asal dari segala sesuatu dan perbuatan itu adalah haram sampai ada dalil yang menunjukkan kebolehannya" 


\section{Mazhab Maliki}

Dalam mazhab ini, hukum merokok tidak dijelaskan secara kongkrit, tetapi dapat dilihat dari sikapnya yang mengaitkannya dengan hukum atau batasan hukum yang lain. Syaikh Khalid bin Ahmad, seorang tokoh pengikut mazhab Maliki berpendapat, tidak dibolehkan bermakmum kepada penghisap rokok, juga kepada orang yang memperjualbelikannya, atau barang-barang lain yang memabukkan. Pernyataan ini menunjukkan bahwa merokok termasuk perbuatan yang tercela, sehingga orang yang menghisapnya atau yang terlibat langsung atau tidak, tidak boleh menjadi imam salat.

\section{Mazhab Syafi'iyyah}

Sebagian ulama kalangan Syafi'iyyah berpendapat bahwa merokok hukumnya haram, yang mengatakan demikian antara lain adalah Abdurrahman alGazzi, Ibrahim bin Jam'an dan muridnya Abu Bakar al-Ahdal, al-Qulyubi, alBuhaerimi, dan lain-lain. Alasan mereka bahwa merokok dapat melemahkan tubuh dan pikiran, walaupun si penghisapnya tidak sampai mabuk. Rasulullah Shallallahu 'Alaihi wa Sallam melarang pemakaian benda yang memabukkan atau melemahkan badan, maka merokok hukumnya haram. ${ }^{17}$

Mereka juga berpendapat bahwa pemakaian sekali atau dua kali tidaklah termasuk dosa besar, tapi jika dilakukan berulang-ulang atau sering maka termasuk dosa besar, sebagaimana berlaku pada dosa-dosa kecil jika dilakukan terusmenerus berubah menjadi dosa besar.

\section{Mazhab Hanbali}

Menurut sebagian ulama dari kalangan Mazhab Hanbali merokok dalam kondisi tertentu hukumnya makruh, namun dalam kondisi tertentu pula dapat menjadi haram. Di antaranya dikemukakan oleh 'Abdullah bin Muhammad dan 'Abdul Wahab. Menurut mereka, tembakau yang berbau tidak sedap, maka makruh memakainya, yang menurut pakar kedokteran dapat membahayakan kesehatan. Jika pemakaiannya berlebihan akan memabukkan bagi si penghisapnya. Terlebih lagi jika mengkonsumsi sesuatu yang membahayakan kesehatan hingga memabukkan, maka hukumnya haram. ${ }^{18}$

\section{Fatwa MUI Tentang Hukum Merokok}

\footnotetext{
${ }^{17}$ Kurdi FadalMob, Kaidah-Kaidah Fiqh, hal 47

${ }^{18}$ Muhammad Ronnurus Shiddiq(2009) Fatwa Majelis Ulama Indonesia Tentang Pengharaman Merokok,76 Vols,hal61-63.
} 
Telah terdapat pada maklumat sebelumnya, bahwa ada fatwa MUI tentang rokok dan atau merokok, sebagai berikut:

Masyarakat mengakui bahwa industri rokok telah memberikan manfaat ekonomi dan sosial yang cukup besar. Industri rokok juga telah memberikan pendapatan yang cukup besar bagi negara. Bahkan, tembakau sebagai bahan baku rokok telah menjadi tumpuan ekonomi bagi sebagian petani. Namun, di sisi yang lain, merokok dapat membahayakan kesehatan (darar) serta berpotensi terjadinya pemborosan (israf) dan merupakan tindakan tabžir.

Secara ekonomi, penanggulangan bahaya merokok juga cukup besar. Pro dan kontra mengenai hukum merokok menyeruak ke publik setelah muncul tunt utan beberapa kelompok masyarakat yang meminta kejelasan hukum merokok. Masyarakat merasa bingung karena ada yang mengharamkan, ada juga yang meminta pelarangan terbatas, dan ada yang meminta tetap pada status makruh.

Menurut ahli kesehatan, rokok mengandung nikotin dan zat lain yang membahayaan kesehatan. Selain kepada perokok, tindakan merokok juga dapat membahayakan orang lain, khususnya yang berada di sekitar perokok. Hukum merokok tidak disebutkan secara jelas dan tegas oleh Al-Qur'an dan sunah/hadis Nabi. Oleh karena itu, fuqaha' mencari solusinya melalui ijtihad. Sebagaimana umumnya masalah yang hukumnya digali lewat ijtihad akan melahirkan perselisihan di antara fuqaha', begitu pula dengan masalah rokok.

\section{Ketentuan Hukum}

Ijtima' Ulama Komisi Fatwa se-Insonesia III sepakat adanya "khilaf mâ baina al-makruh wa al-haram", perbedaan pandangan mengenai hukum merokok, yaitu antara makruh dan haram. Peserta Ijtima'Ulama Komisi Fatwa se-Indonesia III sepakat bahwa merokok hukumnya haram jika dilakukan :

1. Di tempat umum;

2. Oleh anak-anak; dan

3. Ibu Hamil. 19

Salah satu organisasi Islam terbesar di Indonesia yakni Muhammadiyah juga telah menetapkan hukum merokok, yang dikeluarkan oleh Majelis Tarjih dan Tajdid Pimpinan Pusat Muhammadiyah melalui keputusan NO. 6/SM/MTT/III/2010. ${ }^{20}$ Dalam putusan tersebut, Muhammadiyah mengharamkan merokok. Merokok juga pernah dilarang oleh Khalifah Ustmaniy pada abad ke-12

\footnotetext{
${ }^{19}$ Majelis 'Ulama Indonesia, Ijma 'Ulama (Keputusan Ijtima' 'Ulama Komisi Fatwa Se-Indonesia III Tahun 2009) cet 1, Jakarta: 2009

${ }^{20}$ Muhammadiyah, P. P. (2010). Fatwa Majelis Tarjih dan Tajdid Pimpinan Pusat Muhammadiyah No. 6/SM/MTT/III/2010 tentang Hukum Merokok.
} 
BUSTANUL FUQAHA: Jurnal Bidang Hukum Islam

Vol. 1, No. 3 (2020) : Hal. 330-349

Website: https://journal.stiba.ac.id

hijriah dan orang yang merokok dikenakan sanksi, serta rokok yang beredar disita oleh pemerintah, lalu dimusnahkan. ${ }^{21}$

Dewan Fatwa Kerajaan Arab Saudi juga telah mengeluarkan fatwa haram rokok dengan nomor (4947) yang berbunyi, "Merokok hukumnya haram, menanam bahan bakunya (tembakau) juga haram serta memperdagangkannya juga haram, karena rokok menyebabkan bahaya yang begitu besar". ${ }^{22}$

\section{Apakah Merokok Termasuk Pelanggaran Ihram?}

Berkaitan dengan larangan dalam keadaan ihram, kita dapatkan dalam AlQur'an, Allah Ta'ala menjelaskan,

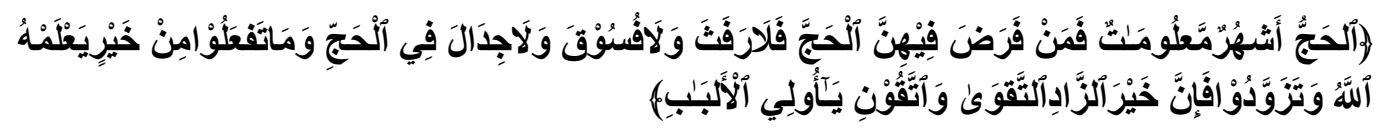

Terjemahnya: "(Musim) haji adalah beberapa bulan yang dimaklumi, barangsiapa yang menetapkan niatnya dalam bulan itu akan mengerjakan haji, maka tidak boleh rafats, berbuat fasik dan berbantah-bantahan di dalam masa mengerjakan haji. Dan apa yang kamu kerjakan berupa kebaikan, niscaya Allah mengetahuinya. Berbekallah, dan sesungguhnya sebaik-baik bekal adalah takwa dan bertakwalah kepada-Ku hai orang-orang yang berakal." (Q.S. Al-Baqarah/2: 197).

Sahabat Ibnu Abbas radiyallahu'anhuma menafsirkan ayat,

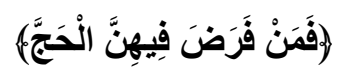

Terjemahnya: "Barangsiapa yang menetapkan niatnya dalam bulan itu akan mengerjakan haji"

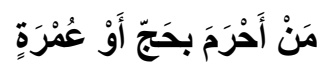

Artinya: "Barangsiapa yang telah melakukan ihram haji atau umrah"

Berkata Ibnu al-Jauzi rahimahullah,

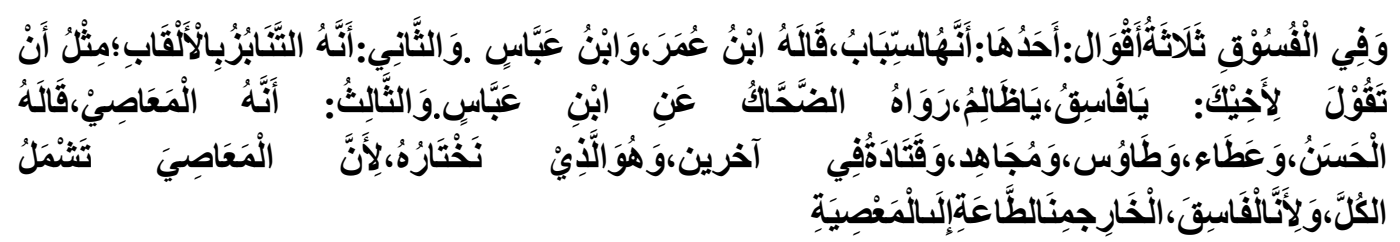

Artinya: 'Dan pada kata 'al-fusuq' terdapat 3 pendapat, yaitu:

\footnotetext{
${ }^{21}$ Erwandi Tarmizi. Harta Haram Muamalat Kontemporer. Bogor: PT.Berkat Mulia Insani, 2017, hal 134.

${ }^{22}$ Ahmad Bin Abdur RazzaqAd-Duwasy.Fatawa AL-Lajnah Ad-Daimah, juz 13 (cet.1:Riyadh, Al idaratul Ammah litthiba, 1428H), hal 31.
} 
1. Mencela, ini adalah tafsiran sahabat Ibnu 'Umar, dan Ibnu 'Abbas;

2. Memanggil dengan gelar-gelar yang buruk, misalnya engkau memanggil saudaramu dengan panggilan, "Wahai fasik, wahai orang zalim", tafsiran ini diriwayatkan oleh adh-Dhohhak dari Ibnu 'Abbas;

3. Kemaksiatan, hal ini disebutkan oleh al-Hasan, 'Atho, Thowus, Mujahid, beserta Qotadah, dan inilah pendapat yang kami pilih, karena maksiat mencakup semua yang telah disebutkan, dan juga karena orang fasik bermakna yang keluar dari ketaatan menuju kemaksiatan."23

Begitu pula diriwayatkan dari Ibnu 'Umar radiyallahu 'anhuma bahwa beliau pernah mengatakan,

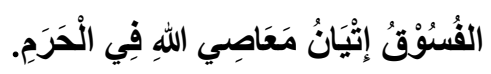

Artinya: “Al-Fusuq (dalam ayat ini adalah) melakukan kemaksiatan kepada Allah di saat berihram atau di daerah haram". ${ }^{24}$

Berkata asy-Syaikh Abdurahman as-Sa'di rahimahullah dalam tafsirnya terkait firman Allah Ta'ala,

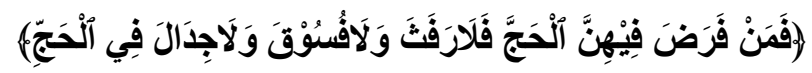

Terjemahnya: "Barangsiapa yang menetapkan niatnya dalam bulan itu akan mengerjakan haji, maka tidak boleh rafas, berbuat fasik dan berbantah-bantahan di dalam masa mengerjakan haji”

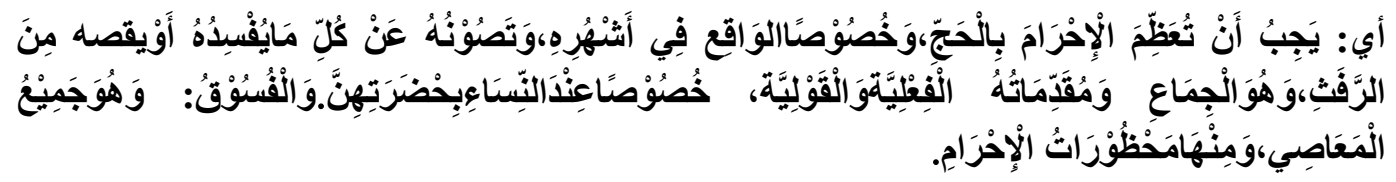

Artinya: "Bermakna wajib bagimu mengagungkan ihram berhaji, khususnya yang berada pada bulan haji, dan menjaganya dari segala yang bisa merusaknya,atau mengurangi pahalanya, di antaranya perbuatan rafas yaitu jimak dan segala yang menjurus kepadanya baik perkataan maupun perbuatan, khususnya di saat berada sekitar wanita. Adapun "al-fusuq", yaitu segala macam bentuk kemaksiatan, di antaranya larangan-larangan dalam berihram". ${ }^{25}$

${ }^{23}$ Jamaluddin Abul Faraj Abdur Rahman bin Aly Bin MuhammadAl -Jauzi. Zadul Masiir Fi 'Ilmi Tafsir1/165.. Beirut: Darul Kitab Al-Arabi 1422H. 1999.

${ }^{24}$ Ismail Ibnu KatsirAl-Dimasyqi. Tafsir Al-Quran Al-Azhim 1/55. Second Ed. Riyadh: Daar Al-Thayyibah,

${ }^{25}$ Abdurrahman bin NashirAl-Sa'diy. Taysiru Karimi Al-Rahman Fii Tafsiri Kalami Al-Mannan. fifth ed. Dammam: Daar Ibnu AL-Jauziy, 2011.hal. 91. 
BUSTANUL FUQAHA: Jurnal Bidang Hukum Islam

Vol. 1, No. 3 (2020) : Hal. 330-349

Website: https://journal.stiba.ac.id

Adapun merokok termasuk maksiat karena hukumnya haram sebagaimana pemaparan sebelumnya. Dengan demikian, dalam hal ini merokok termasuk pelanggaran dalam berihram.

\section{Apakah Merokok Membatalkan Ibadah Orang yang Melakukan Haji dan Umrah?}

Merokok, selain bisa membahayakan dirinya, dapat membahayakan orang yang di sekitarnya, juga termasuk perbuatan tidak mengagungkan syiar Allah, karena tidak sedikit penulis saksikan bahwa mereka merokok sekalipun di saat di daerah haram dan masyarilharam terlebih lagi saat wukuf di arafah.

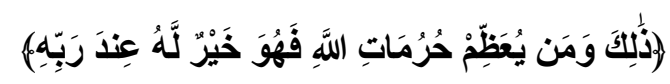

Terjemahnya: "Demikianlah (perintah Allah). Dan barang siapa mengagungkan apa yang terhormat di sisi Allah (hurumat) maka itu lebih baik baginya di sisi Tuhannya". (Q.S. Al-Hajj/22: 30).

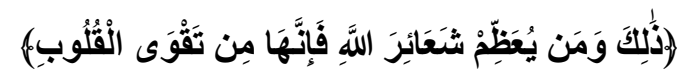

Terjemahnya: "Demikianlah (perintah Allah). Dan barangsiapa mengagungkan syiar-syiar Allah, maka sesungguhnya hal itu timbul dari ketakwaan hati”. (Q.S. Al-Hajj/22: 32)

Dampak negatif dari kebiasaan merokok dapat dirasakan penghisapnya dalam jangka pendek, di antaranya menyebabkan bau pada badan, pakaian dan berimbas ke pada orang di sekitarnya. Padahal setelah memakan bawang saja dilarang ke masjid karena baunya yang tak sedap apalagi bau rokok ini, berdampak saat berihram haji atau umrah, padahal dalam hadis disebutkan, bahwa Rasulullah Shallallahu 'Alaihi wa Sallam bersabda,

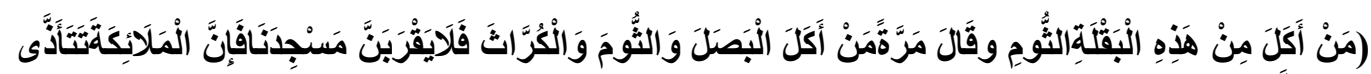

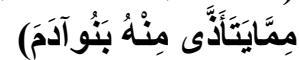

Artinya: "Barangsiapa yang makan sayuran bawang putih ini, dan pada kesempatan lain beliau bersabda, 'Barangsiapa makan bawang merah dan putih serta bawang bakung, janganlah dia mendekati masjid kami, karena malaikat merasa tersakiti dari bau yang juga manusia merasa tersakiti (disebabkan baunya)"'26

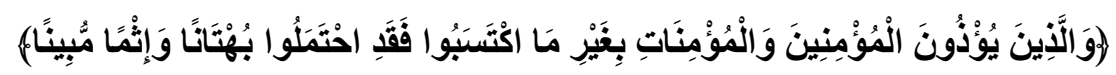

${ }^{26}$ Muslim Bin Al-HajjajAn-Naisaburi. Shahih Muslim. Kitab Al-Masajid Wa Mawadhi' Ash-Shalah, Bab Nahy Man Akala Tsuman, Nomor 564.Beirut: Darul Kutub Al-'Ilmiyah, 1414H. 
BUSTANUL FUQAHA: Jurnal Bidang Hukum Islam

Vol. 1, No. 3 (2020) : Hal. 330-349

Website: https://journal.stiba.ac.id

Terjemahnya: "Dan orang-orang yang menyakiti atau menganggu orang-orang mukmin laki-laki dan perempuan, tanpa ada kesalahan yang mereka perbuat, maka sungguh, mereka telah memikul kebohongan dan dosa yang nyata". (Q.S. AlAhzab/33: 58).

Selain itu di antara jemaah haji atau umrah yang membawa rokok dalam jumlah banyak untuk diperjualbelikan di sana, bahkan ditemukan pembimbing membagi-bagikan rokok yang banyak tersebut ke beberpa jemaah bimbingannya untuk dimasukkan ke dalam koper masing-masing agar tidak terlihat banyak di saat pemeriksaan dan kemudian mereka serahkan setibanya di sana untuk diperjualbelikan. Tentunya, karena merokok itu haram sehingga hasil jual belinya pun haram.

Berdasarkan hadis Nabi Shallallahu 'Alayhi wa Sallam,

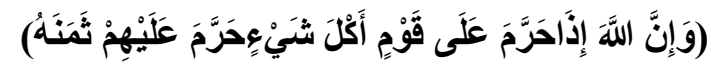

Artinya: "Sesungguhnya Allah apabila mengharamkan atas suatu kaum memakan sesuatu, berarti Allah mengharamkan juga hasil penjualannya."27

Allah Ta’ala juga telah melarang kita untuk tolong menolong dalam perbuatan dosa,"

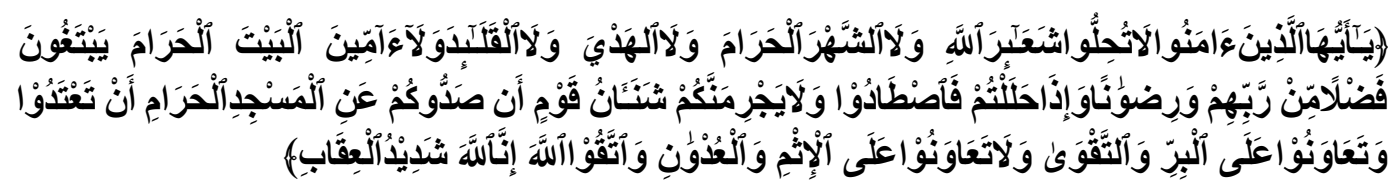

Terjemahnya: "Wahai orang-orang yang beriman! Janganlah kamu melanggar syiar-syiar kesucian Allah, dan jangan (melanggar kehormatan) bulan-bulan haram, jangan (mengganggu) hadyu (hewan-hewan kurban) dan qala'id (hewanhewan kurban yang diberi tanda), dan jangan (pula) mengganggu orang-orang yang mengunjungi Baitulharam; mereka mencari karunia dan keridaan Tuhannya. Tetapi apabila kamu telah menyelesaikan ihram, maka bolehlah kamu berburu. Jangan sampai kebencian(mu) kepada suatu kaum karena mereka menghalanghalangimu dari Masjidil haram, mendorongmu berbuat melampaui batas (kepada mereka). Dan tolong-menolonglah kamu dalam (mengerjakan) kebajikan dan takwa, dan jangan tolong-menolong dalam berbuat dosa dan permusuhan. Bertakwalah kepada Allah, sungguh, Allah sangat berat siksaan-Nya”. (Q.S. AlMaidah/5: 2).

${ }^{27}$ Abu Daud SulaimanAs-Sijistani. Sunan Abi Daud. Kitab Al-Ijarah, Bab Fi Tsamani Al-Khamr Wa Al-Maitah, Nomor 3488. Dimasyq: Dar Ar-Risalah Al-'Alamiyah. $1430 \mathrm{H}$. 
Ayat ini juga menjelaskan agar tidak melanggar syiar-syiar Allah dan larangan untuk menganggu orang terutama yang mendatangi Baitullah. Tentu pula dikhawatirkan bahwa tidak dikabulkan doanya orang yang melakukan perbuatan tersebut ,sebagaimana dalam hadits,

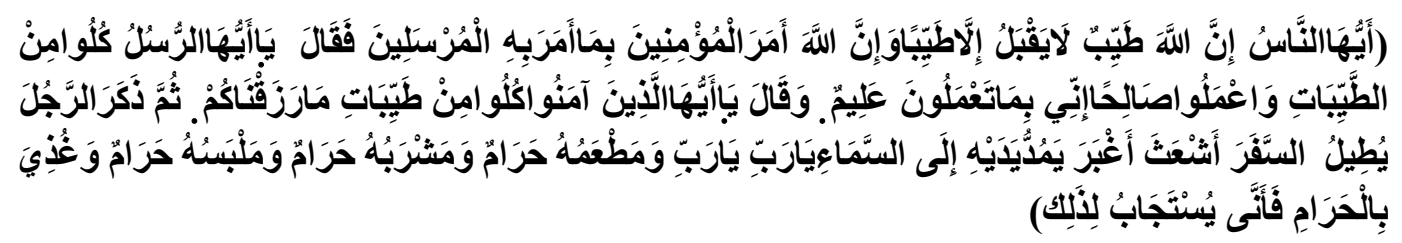

Artinya: "Wahai sekalian manusia, sesungguhnya Allah itu baik. Dia tidak akan menerima sesuatu melainkan yang baik pula. Dan sesungguhnya Allah telah memerintahkan kepada orang-orang mukmin seperti yang diperintahkan-Nya kepada para Rasul. Firman-Nya: 'Wahai para Rasul! Makanlah makanan yang baik-baik (halal) dan kerjakanlah amal salih. Sesungguhnya Aku Maha Mengetahui apa yang kamu kerjakan.' Dan Allah juga berfirman: 'Wahai orangorang yang beriman! Makanlah rezeki yang baik-baik yang telah menceritakan kepada Kami, telah Kami rezekikan kepadamu." Kemudian Nabi Shallallahu 'Alaihi Wasallam menceritakan tentang seorang laki-laki yang telah lama berjalan karena jauhnya jarak yang ditempuhnya. Sehingga rambutnya kusut, masai dan berdebu. Orang itu mengangkat tangannya ke langit seraya berdoa: "Wahai Tuhanku, wahai Tuhanku." Padahal, makanannya dari barang yang haram, minumannya dari yang haram, pakaiannya dari yang haram dan diberi makan dengan makanan yang haram, maka bagaimanakah Allah akan mengabulkan doanya?."28

Namun, apakah menyebabkan haji atau umrahnya tidak sah?. Berkata Syekh Muhammad al-'Utsaimin rahimahullah:

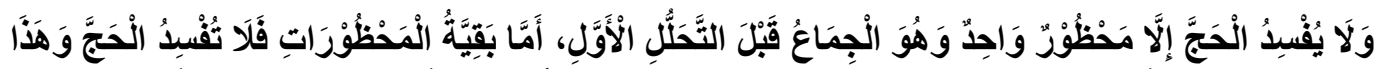

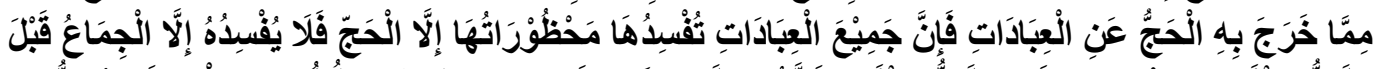

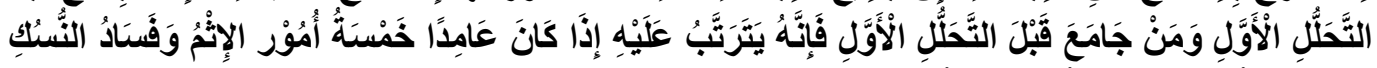

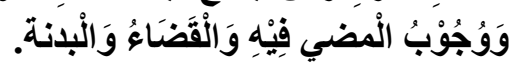

Artinya: "Haji tidaklah rusak atau batal (dengan melakukan larangan-larangan ihram) kecuali satu larangan yaitu jimak sebelum tahalul pertama, adapun selainnya tidak merusak ibadah hajinya, inilah di antara kekhususan haji yang berbeda dengan ibadah lainnya, di mana semua ibadah selain dari pada haji bisa rusak atau batal dengan melanggar larangan-larangannya. Maka barang siapa yang

${ }^{28}$ Muslim Bin Al-HajjajAn-Naisaburi. Shahih Muslim. Kitab Az-Zakah, Bab Qabul Ash-Shadaqah Min Al-Kasb Ath-Thayyib Wa Tarbiyatuha, Nomor 1015.Beirut: Darul Kutub Al-'Ilmiyah, 1414H. 
BUSTANUL FUQAHA: Jurnal Bidang Hukum Islam

Vol. 1, No. 3 (2020) : Hal. 330-349

Website: https://journal.stiba.ac.id

melakukan jimak dengan sengaja saat berihram sebelum tahalul pertama, maka akan berakibat 5 hal yaitu, berdosa, rusak atau batal ibadah hajinya, mengulang hajinya, dan membayar fidiah". ${ }^{29}$

Adapun Syekh Bin Baz rahimahullah berkata:

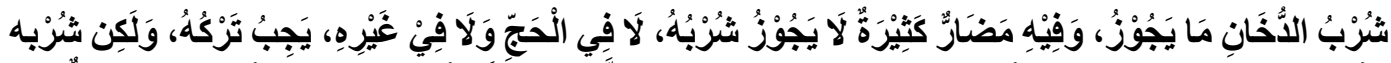

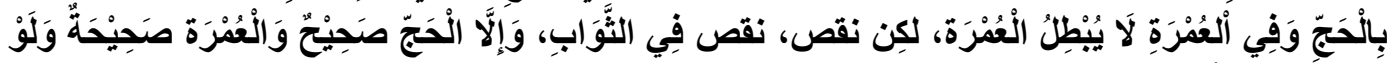

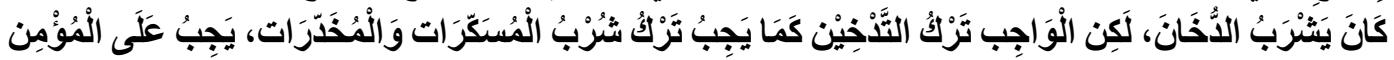

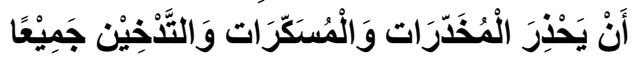

Artinya: "Merokok itu terlarang, padanya zat-zat yang berbahaya yang tidak boleh dikomsumsi baik pada saat haji maupun selainnya, wajib untuk meninggalkannya. Namun, merokok saat berhaji dan atau umrah tidak membatalkan ibadah tersebut, akan tetapi dapat mengurangi pahalanya. Dan wajib untuk meninggalkannya, berhenti darinya sebagaimana wajib untuk meninggalkan khamar, narkoba dan semacamnya". 30

Namun, tentunya persoalan diterima tidaknya kembali kepada kehendak Allah Ta'ala. Oleh karena itu, bagi yang pernah melakukannya saat berumrah atau berhaji, maka bertaubat dan beristigfar, semoga Allah Ta'ala menerima taubat dan ibadah haji atau umrahnya. Allah Ta'ala berfirman,

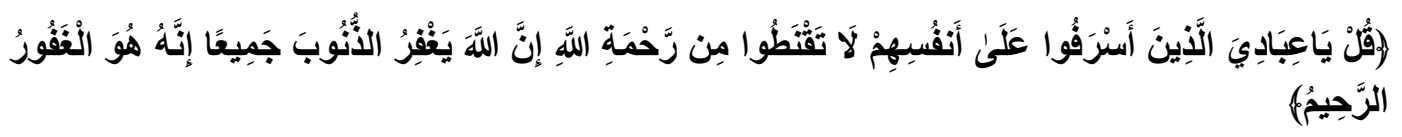

Terjemahnya: "Katakanlah, "Wahai hamba-hamba-Ku yang melampaui batas terhadap diri mereka sendiri! Janganlah kamu berputus asa dari rahmat Allah. Sesungguhnya Allah mengampuni dosa-dosa semuanya. Sungguh, Dialah Yang Maha Pengampun, Maha Penyayang." (Q.S. Al-Zumar/39: 53).

Dalam ayat yang lain,

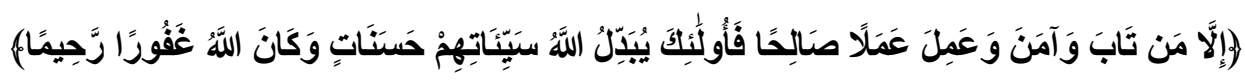

Terjemahnya: "Kecuali orang-orang yang bertobat dan beriman dan mengerjakan kebajikan; maka kejahatan mereka diganti Allah dengan kebaikan. Allah Maha Pengampun, Maha Penyayang." (Q.S. Al-Furqan/25: 70).

4 hal 82.

${ }^{29}$ Muhammad Bin Shalih Bin Muhammad Al-Utsaimin, Ta'liqat Ibn Utsaimin 'Ala Al-Kafi Li Ibn Qudamah juz

${ }^{30}$ Abdul Aziz Bin Abdillah Bin Baz. Majmu' Fatawa. Nur 'Ala Ad-Darb,Riyadh: Dar Al-Qosim, 1420H.Hal 68. 
BUSTANUL FUQAHA: Jurnal Bidang Hukum Islam

Vol. 1, No. 3 (2020) : Hal. 330-349

Website: https://journal.stiba.ac.id

Dalam ayat yang lain pula, Allah Ta'ala berfirman,

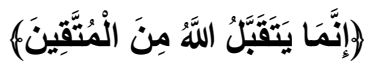

Terjemahnya: "Sesungguhnya Allah hanya menerima (amal) dari orang yang bertakwa."(Q.S. Al-Maidah/5: 27).

Adapun untuk yang akan melaksanakan ibadah haji atau umrah agar memperhatikan hal ini khususnya bagi para perokok aktif. Begitu juga para pembimbing untuk terus mengarahkan dan mengingatkan jemaahnya agar tidak terjatuh dalam pelanggaran dalam berhaji atau umrah, termasuk kebiasan buruk ini.

\section{KESIMPULAN}

Tujuan yang ingin dicapai dari penelitian ini adalah untuk mengetahui hukum merokok saat melakukan ibadah haji atau umrah. Sementara hasil dari penelitian ini adalah bahwa merokok hukumnya haram sehingga termasuk perbuatan fasik atau maksiat yang mana merupakan di antara larangan-larangan dalam berihram haji atau umrah, namun tidak sampai membatalkan ibadah haji dan umrahnya, hanya saja bisa mengurangi pahalanya atau bahkan tidak mendapatkan haji yang mabrur atau umrah yang maqbulah di sisi Allah, sebagaimana dalam hadis:

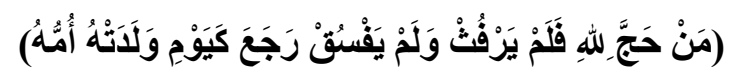

Artinya: "Barangsiapa melakukan haji ikhlas karena Allah tanpa berbuat keji dan kefasiqan, maka ia kembali tanpa dosa sebagaimana waktu ia dilahirkan oleh ibunya." "31

Begitu juga hadis-hadis lainnya yang menjelaskan keutamaan haji dan umrah.

\section{DAFTAR PUSTAKA}

Abdul Aziz Bin Abdillah Bin Baz. (1420H). Majmu' Fatawa. Riyadh:Dar AlQosim.

Ad-Duwasy, Ahmad Bin AbdurRazzaq. (1428H). Fatawa AL-Lajnah Ad-Daimah, cet.1:Riyadh,Al idaratul Ammah litthiba.

${ }^{31}$ Muhammad Bin IsmailAl-Bukhari, Shahih Al-Bukhari,Kitab Al-Hajj, Bab Fadhl Al-Hajj Al-Mabrur, Nomor 1521. Dar Thariq An-Najah, 1422H. 
BUSTANUL FUQAHA: Jurnal Bidang Hukum Islam

Vol. 1, No. 3 (2020) : Hal. 330-349

Website: https://journal.stiba.ac.id

Al-Jauzi, Jamaluddin Abul Faraj AbdurRahman bin Aly Bin Muhammad. (1422H). Zadul Masiir Fi 'Ilmi Tafsir. Beirut: Darul Kitab Al-Arabi.

Al-Bukhari, Muhammad Bin Ismail. (1422H). Shahih Al-Bukhari, Dar Thariq AnNajah,.

Al-Dimasyqi, Ismail Ibnu Katsir. (1999). Tafsir Al-Quran Al-Azhim. Second Ed. Riyadh: Daar Al-Thayyibah.

Al-Qozwini, Muhammad Bin Yazid. (2009). Sunan Ibnu Majah, Kairo: Dar Ihya Al-Kutub Al-Arabiyah.

Al-Sa'diy, Abdurrahman bin Nashir. (2011). Taysiru Karimi Al-Rahman Fii Tafsiri Kalami Al-Mannan. fifth ed. Dammam: Daar Ibnu AL-Jauziy.

Al-Utsaimin, Muhammad Bin Shalih Bin Muhammad. (t.th.). Ta'liqat Ibn Utsaimin 'Ala Al-Kafi Li Ibn Qudamah.

An-Naisaburi, Muslim Bin Al-Hajjaj. (1414H). Shahih Muslim. Beirut: Darul Kutub Al-'Ilmiyah,.

AS-Sijistani, Abu Daud Sulaiman. (1430 H). Sunan Abi Daud. Dimasyq: Dar ArRisalah Al-'Alamiyah..

As-Syaibani, Ahmad Bin Hanbal. (1421H). Musnad Al-Imam Ahmad. Beirut: Muassasah Ar-Risalah.

At-Tirmidzi, Muhammad bin 'Isa. (1395 H). Sunan At-Tirmidzi, Cet.2:Mesir,Syarikah Musthofah.

Batubara, I. V. D., Wantouw, B., \& Tendean, L. (2013). Pengaruh paparan asap rokok kretek terhadap kualitas spermatozoa mencit jantan (mus musculus). eBiomedik, 1(1).

Tarmizi, E. (2017). Harta Haram Muamalat Kontemporer. Bogor: PT.Berkat Mulia Insani.

Hammado, N. "Pengaruh Rokok Terhadap Kesehatan dan Pembentukan Karakter Manusia." Prosiding 1.1 (2014): 77-84.

Li, X., Lin, B., Zhang, H., Xie, F., Ta, N., Tian, L., ... \& Xi, Z. (2016). Cytotoxicity and mutagenicity of sidestream cigarette smoke particulate matter of different particle sizes. Environmental Science and Pollution Research, 23(3), 2588-2594.

Majelis 'Ulama Indonesia. (2009). Ijma 'Ulama (Keputusan Ijtima' 'Ulama Komisi Fatwa Se-Indonesia III Tahun 2009), cet 1, Jakarta.

Mangku, S. (2000). Kekhususan Rokok Indonesia. Jakarta: PT Gramedia.

Muchtar A. F. (2009). Siapa Bilanng Merokok Makruh?, Jakarta: PT Bhuana Ilmu Populer.

Muhammadiyah, P. P. (2010). Fatwa Majelis Tarjih dan Tajdid Pimpinan Pusat Muhammadiyah No. 6/SM/MTT/III/2010 tentang Hukum Merokok.

Muhammad Jaya. (2009). Pembunuh Berbahaya Itu Bernama Rokok. Yogyakarta: Rizma. 
BUSTANUL FUQAHA: Jurnal Bidang Hukum Islam

Vol. 1, No. 3 (2020) : Hal. 330-349

Website: https://journal.stiba.ac.id

Samosir, D. S. N., Priyatna, C. C., \& Hafiar, H. (2019). Makna Pictorial Health Warning Pada Kemasan Rokok Dalam Mengomunikasikan Pesan Bahaya Merokok. Jurnal Nomosleca, 5(1).

Shiddiq, Muhammad Ronnurus. (2009). Fatwa Majelis Ulama Indonesia Tentang Pengharaman Merokok, 76 Vols.

Supardi. (2009). Merokok dan Transaksi Jual Beli Rokok dalam Pandangan Hukum Islam, Skripsi UIN Sunan Kalijaga Yogyakarta 